\title{
Interaction of the Receptor for Advanced Glycation End Products (RAGE) with Transthyretin Triggers Nuclear Transcription Factor kB (NF-kB) Activation
}

\author{
Mónica Mendes Sousa, Shi Du Yan, David Stern, and Maria João Saraiva \\ Amyloid Unit (MMS, MJS), Instituto de Biologia Molecular e Celular, and Instituto de Ciências Biomédicas Abel \\ Salazar (MMS, MJS), Universidade do Porto, Portugal; and Department of Physiology (SDY, DS), Columbia \\ University, New York
}

\begin{abstract}
SUMMARY: Mutated transthyretin (TTR) fibrils are associated with the pathology of familial amyloidotic polyneuropathy (FAP), in which extracellular amyloid deposits lead to degeneration of cells and tissues, in particular neurons of the peripheral nerve. Here we present evidence that the receptor for advanced glycation end products (RAGE), previously associated with Alzheimer's disease, acts as a selective cell surface acceptor site for both soluble and fibrillar TTR. Immunohistochemical studies demonstrating increased expression of RAGE in FAP tissues suggested the relevance of this receptor to TTR-induced fibrillar pathology. In vitro studies using soluble RAGE showed saturable specific interaction with soluble and fibrillar TTR with a $\mathrm{K}_{\mathrm{d}}$ of $\sim 120 \mathrm{nM}$. However, no binding was observed when soluble TTR was combined with retinol-binding protein, which represents the form in which TTR normally circulates in plasma. Specific binding of TTR to RAGE-transfected Chinese hamster ovary cells (which was completely blocked by anti-RAGE) was observed, confirming that RAGE could mediate TTR binding to cellular surfaces. RAGE-dependent activation of nuclear transcription factor kB (NF-kB) by TTR fibrils was shown in PC-12 cells stably transfected to overexpress the receptor. Furthermore, FAP nerves showed up-regulation of p50, one of the NF-kB subunits, when compared with age-matched controls. From these observations we predict that, in vivo, the presence of TTR fibrils associated with cellular surfaces of FAP patients, by contributing to NF-kB activation, leads to the pathogenesis of neurodegeneration. Further insights into the consequences of the interaction of fibrillar TTR with RAGE may therefore provide a better understanding of neurodegeneration associated with FAP. (Lab Invest 2000, 80:1101-1110).
\end{abstract}

$F$ amilial amyloidotic polyneuropathy (FAP) is a extracellular deposition of transthyretin (TTR) fibrils in several tissues, particularly in the peripheral nervous system (Saraiva, 1995). In the peripheral nerves, amyloid infiltrates the epineurium, the perineurium, and especially the endoneurium. Extensive amyloid deposition is also observed in the meninges, in the spinal and autonomic ganglia, throughout the connective tissue, and in a perivascular distribution. In contrast, no amyloid deposition is detected in the brain. Mutated TTR is the main component of these amyloid fibrils. Several mutations in TTR have been described, the most common being a valine (Val) for methionine (Met) substitution at position 30 of the protein (Val30Met) (Saraiva et al, 1983). Nonmutated TTR also deposits as amyloid in senile amyloidosis (Gustavsson et al, 1995). TTR is a plasma homotetrameric protein of approximately $55 \mathrm{kDa}$ produced early in development and highly conserved in evolution (Blake et al,

Received March 30, 2000.

This work was supported by a grant from PRAXIS XXI (SAU/1290/95) from Portugal. M. M. Sousa is a recipient of a scholarship from the Gulbenkian Ph.D. Program in Biology and Medicine.

Address reprint requests to: Maria João Saraiva, Amyloid Unit, Instituto de Biologia Molecular e Celular, R. Campo Alegre, 823. 4150 Porto, Portugal; Fax: 351-22-6099157; E-mail:mjsaraiv@ibmc.up.pt
1974). TTR functions as a carrier for thyroxine $\left(T_{4}\right)$ and retinol (vitamin A) (Raz et al, 1970) by formation of a complex with retinol-binding protein (RBP). Under physiological conditions, TTR circulates as a 1:1 molar complex with RBP.

In Alzheimer's disease, another amyloid related disorder, intracellular and extracellular deposits of filamentous proteins are associated with neuronal dysfunction leading to dementia (Selkoe et al, 1999; Sisodia and Price, 1995). Spatial association between amyloid $\beta$-peptide $(A \beta)$-containing plaques and neurons with signs of cellular oxidant stress has been reported in Alzheimer's disease (Hensley et al, 1994; Behl et al, 1994; Smith et al, 1996), suggesting that interaction of $A \beta$ with cellular surfaces could underlie chronic neuronal dysfunction. A reasonable candidate for mediating such effects would be cell surface acceptor sites. Several possible receptors/binding sites for A $\beta$ have been reported (Boland et al, 1996; Du Yan et al, 1997; Giulian et al, 1998; LaFerla et al, 1997; Matter et al, 1998; Shen et al, 1998; Yaar et al, 1997; Yan et al, 1996), and recent attention has focused on the receptor for advanced glycation endproducts (RAGE) because of its potential to function as a signal transduction receptor for $\beta$-sheet fibrils (Du Yan et al, 1997; Kindy et al, 1999; Yan et al, 1996, 1999). Although RAGE was initially identified by its interaction with products of nonenzymatic glycoxidation, this 55 
$\mathrm{kDa}$ member of the immunoglobulin superfamily has been shown to have properties of a multiligand receptor, analogous to other family members (Hofmann et al, 1999; Hori et al, 1995; Kislinger et al, 1999; Schmidt et al, 1992, 1999). In addition to advanced glycation endproducts (Kislinger et al, 1999; Schmidt et al, 1992, 1999), diverse ligands of RAGE include amphoterin (Hori et al, 1995), S100/calgranulins (Hofmann et al, 1999), and $A \beta$ (as well as amyloids forming $\beta$-sheet fibrils composed of other subunits, such as amylin, serum amyloid $A$, and prion protein (Du Yan et al, 1997; Kindy et al, 1999; Yan et al, 1996, 1999). Key properties of RAGE that support its potential to participate in chronic cellular perturbation underlying organ dysfunction in amyloidoses include enhanced and sustained expression of functional receptor at sites of ligand deposition (Schmidt et al, 1999). Thus, although RAGE is expressed at varying levels in normal tissues, it is prominently enhanced at sites of tissue pathology. In the view of the reasonable hypothesis that common pathways probably underlie different amyloid related disorders, and because TTR has a high $\beta$ sheet content, we investigated whether TTR fibrils would also specifically bind RAGE, thus inducing cellular stress, and whether tissues with deposition of TTR fibrils would show increased RAGE expression.

\section{Results}

\section{TTR and RAGE Immunohistochemistry}

Affected tissues from patients with FAP (Fig. 1, A and B) were studied to evaluate expression of RAGE and TTR deposition. In lung vasculature, a patient with FAP (Val30Met) demonstrated increased levels of RAGE in the endothelium and smooth muscle cells (Fig. 1A, middle), compared with the control sample (Fig. 1A, right). The distribution of immunoreactive TTR appeared to overlap that for RAGE (Fig. 1A, left). In sections of peripheral nerve from an FAP patient, levels of RAGE expression (Fig. 1B, middle) were increased compared with the control sample (Fig. 1B, right). Again, TTR deposition in the FAP nerve (Fig. 1B, left) overlapped, at least in part, that for RAGE. The apparent juxtaposition of RAGE and TTR suggested the possibility that RAGE-TTR interaction might be relevant to the pathobiology of FAP.

\section{Binding of TTR to RAGE}

We started by investigating, in vitro, the interaction of soluble TTR (sTTR) with soluble RAGE (sRAGE). When the concentration of SRAGE adsorbed to the wells was held constant (5 $\mu \mathrm{g} /$ well), binding of $\mathrm{s}^{125} \mathrm{I}$-TTR was

$\mathbf{A}$

TTR

LUNG

B

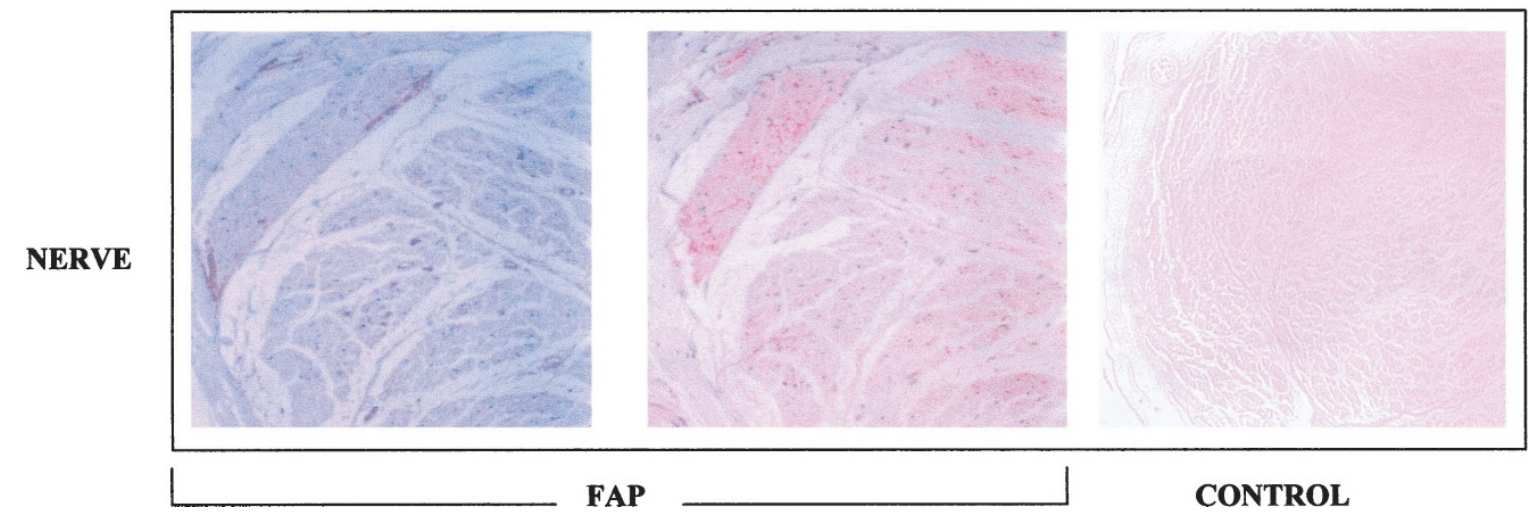

Figure 1.

Mutated transthyretin (TTR) and receptor for advanced glycation end products (RAGE) immunohistochemistry of familial amyloidotic polyneuropathy (FAP) (left and middle panels) and non-FAP control (right panel) tissues. A, Lung sections: TTR immunostaining (left panel) and RAGE immunostaining (middle and right panels). $B$, Nerve sections: TTR immunostaining (left panel) and RAGE immunostaining (middle and right panels). 
dose dependent, specific, and saturable, with an apparent $\mathrm{K}_{\mathrm{d}}$ of approximately $120 \mathrm{~nm}$ (Fig. 2A). Addition of either cold TTR, soluble RAGE, or anti-RAGE IgG, simultaneously with $\mathrm{s}^{125} \mathrm{I}-\mathrm{TTR}$, resulted in dosedependent inhibition of binding, whereas nonimmune rabbit IgG (NI) had no effect (Fig. 2B).

To test whether RAGE would bind directly to fibrillar TTR, synthetic wild-type TTR fibrils were adsorbed to microtiter wells and specific binding of ${ }^{125}$ I-RAGE was assayed. Fibrillar TTR bound ${ }^{125} \mathrm{I}$-RAGE in a specific and saturable fashion, with a $\mathrm{K}_{\mathrm{d}}$ of approximately 120 $\mathrm{nm}$ (Fig. 3A). Binding was abolished by molar excess of cold sRAGE and anti-RAGE IgG, as for sTTR (data not shown).
Because both soluble and fibrillar TTR displayed virtually identical binding properties towards RAGE, we assessed whether the physiologic form of TTR, that combined with RBP, would interact with the receptor. In the presence of RBP, soluble TTR did not display binding to RAGE (Fig. 3B). In contrast, addition of RBP to fibrillar TTR was without effect on its ability to interact with RAGE (Fig. 3B). The latter result was expected, because RBP does not bind to TTR fibrils.

\section{Binding of ${ }^{125}$ I-TTR to RAGE Transfected Cells}

Because sTTR and fibrillar TTR bound sRAGE with the same approximate affinity, we reasoned that RAGE

A

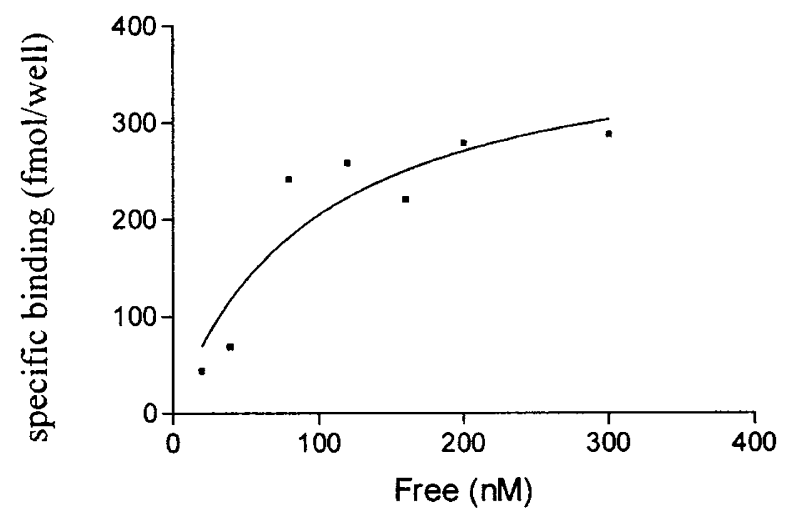

$\mathbf{B}$

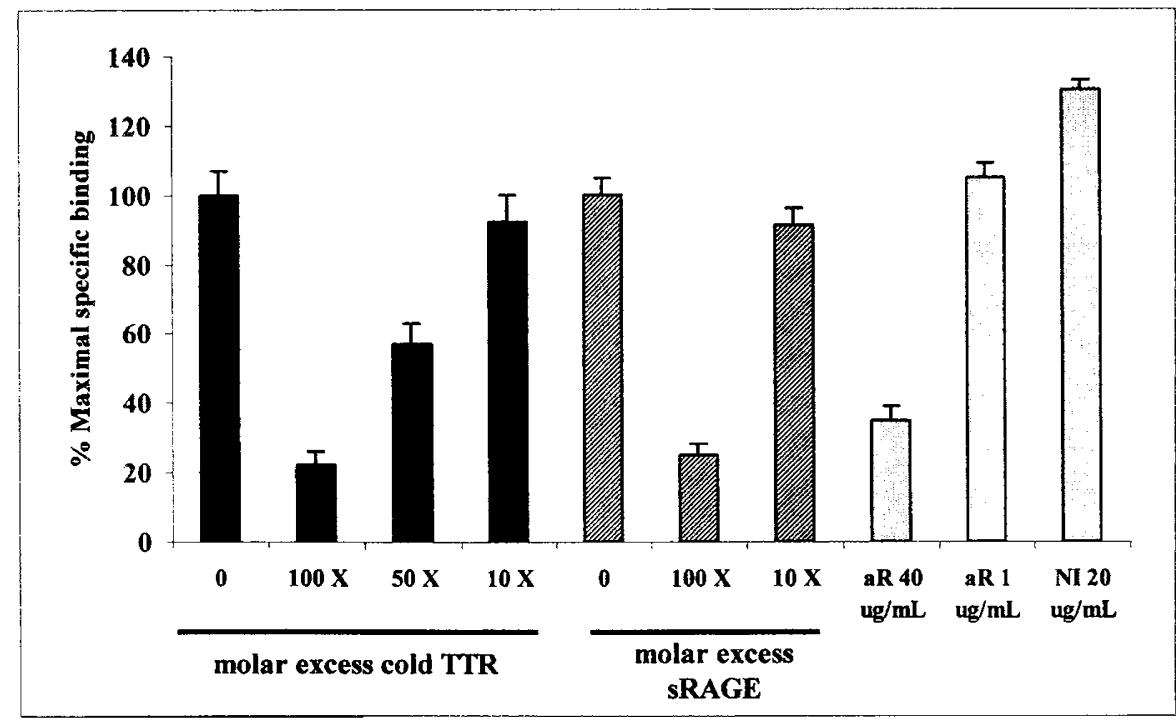

\section{Figure 2.}

A, Binding of soluble ${ }^{125}$ I-TTR ( $\mathrm{s}^{125}$ I-TTR) to purified soluble RAGE (SRAGE) immobilized in microtiter wells $\left(5 \mu \mathrm{g} /\right.$ well). The indicated concentration of ${ }^{125}$ I-TTR was added to wells pre-incubated with sRAGE and specific binding was assessed. B, $100 \mathrm{nM}$ of $\mathrm{s}^{125}$ /-TTR were added to each well in the presence or absence of the indicated concentration of cold sTTR, sRAGE, anti-RAGE (aR), or nonimmune IgG (NI) $(20 \mu \mathrm{g} / \mathrm{ml})$. 


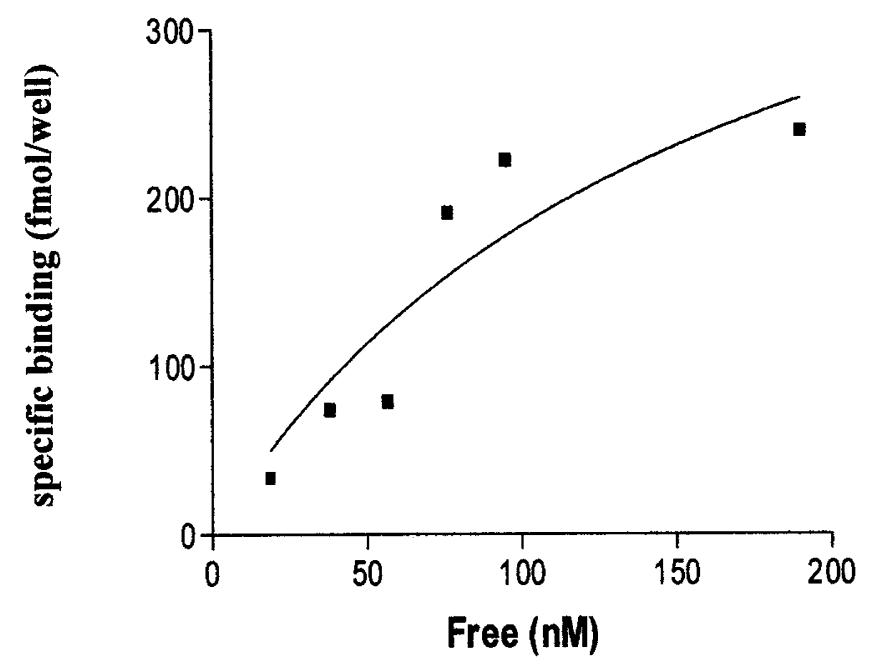

B

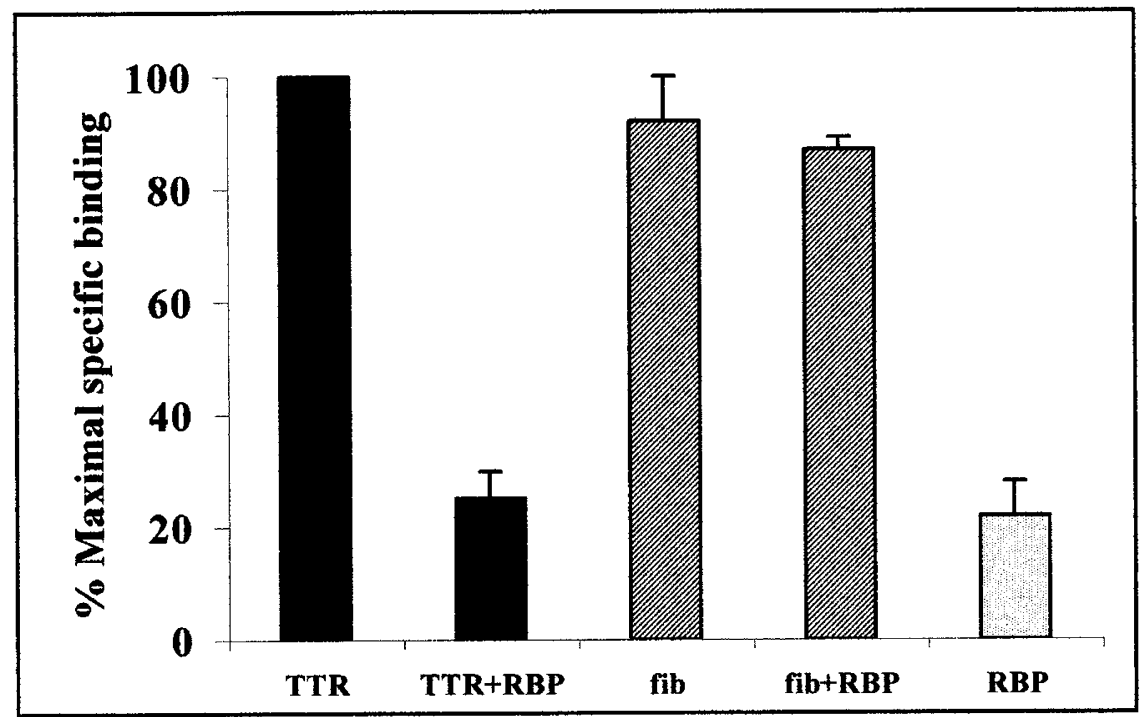

\section{Figure 3.}

A, Binding of ${ }^{125}$ I-RAGE at the indicated concentrations to fibrillar TTR immobilized on microtiter wells $\left(5 \mu \mathrm{g} /\right.$ well). B, Binding of ${ }^{125}$-RAGE (100 nM) to different proteins immobilized on microtiter wells: $5 \mu \mathrm{g} /$ well soluble TTR (TTR); $5 \mu \mathrm{g}$ soluble TTR combined with retinol-binding protein (RBP) (TTR+RBP); $5 \mu \mathrm{g}$ fibrils (fib); $5 \mu \mathrm{g}$ of fibrils incubated with RBP (fib+RBP); RBP alone (RBP).

could serve as a cell-surface acceptor site for sTTR and/or fibril TTR. To confirm that RAGE could mediate the binding of STTR and/or fibril TTR to cells, Chinese hamster ovary $(\mathrm{CHO})$ cells transfected with a RAGEcontaining construct were studied using a radioligand binding assay (RAGE expression in transfected $\mathrm{CHO}$ cells was confirmed before binding studies). Specific, dose-dependent and saturable binding of ${ }^{125}$ I-sTTR with a $\mathrm{K}_{\mathrm{d}}$ of approximately $105 \mathrm{~nm}$ was observed, whereas mock transfected $\mathrm{CHO}$ cells bound ${ }^{125}$ I-TTR minimally (Figure 4A). Binding of ${ }^{125}$ I-TTR to $\mathrm{CHO}$ cells transfected to overexpress RAGE was blocked by 
A

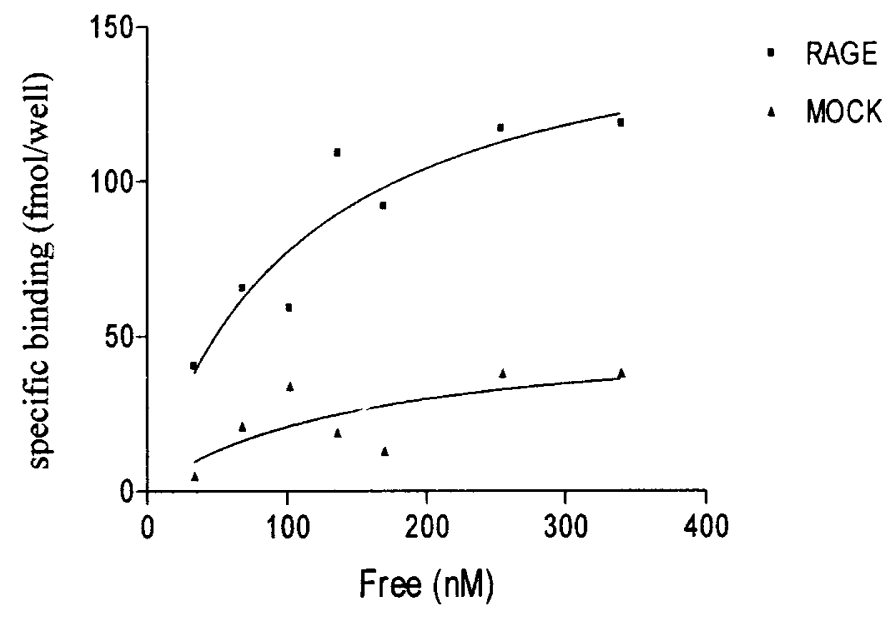

B

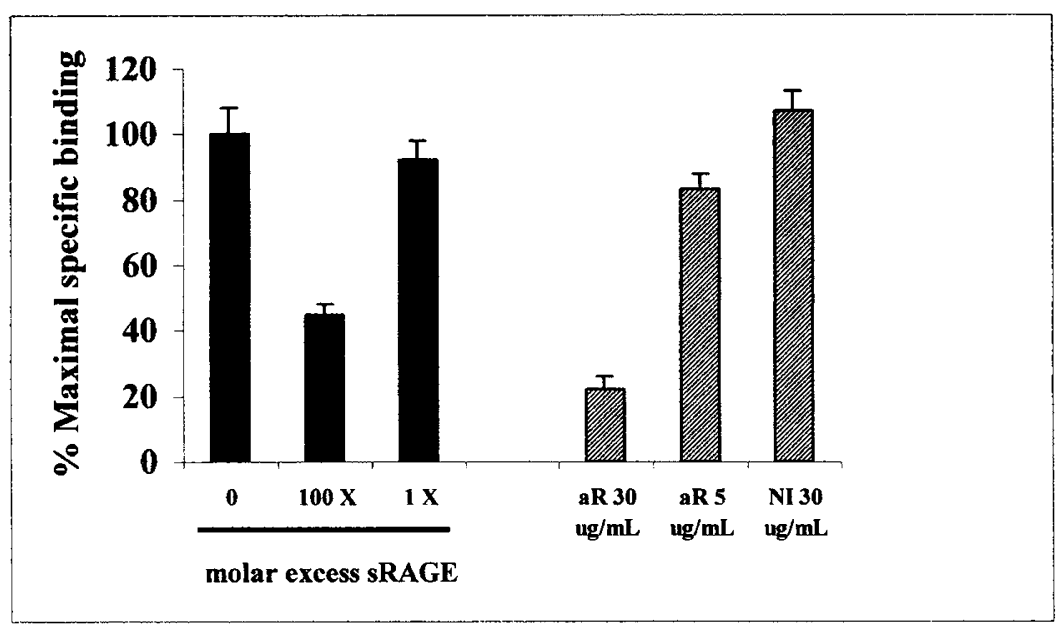

Figure 4.

A, Binding of ${ }^{125}$ I-sTTR (added at the indicated concentration) to RAGE and mock-transfected Chinese hamster ovary (CHO) cells. B, Binding of ${ }^{125}$ I-sTTR (100 nM) to RAGE transfected $\mathrm{CHO}$ cells plated in microtiter wells in the presence of the indicated concentration of sRAGE, anti-RAGE IgG (aR), or nonimmunne IgG (NI).

anti-RAGE IgG, whereas nonimmune IgG had no inhibitory effect (Fig. 4B). Binding was also inhibited by molar excess of sRAGE (Fig. 4B). These data indicate that RAGE is a binding site for sTTR and, most likely, for TTR fibrils on cellular surfaces.

\section{NF-kB Activation}

To ascertain consequences of TTR engagement of cell surface RAGE, nuclear translocation of nuclear transcription factor kB (NF-kB) was studied. The binding of nuclear proteins to a consensus NF-kB probe was demonstrated using electrophoretic mobility shift assay and nuclear extracts of PC12 cells stably transfected to overexpress RAGE exposed to TTR. Cells exposed to sTTR demonstrated activation of NF-kB above background levels (Fig. 5A, lanes 3 and 4). The sTTR-induced gel shift band was blocked when the protein was previously incubated with RBP (Fig. 5A, lane 5), demonstrating again that the physiological form of the protein, ie, in a complex with RBP, is not able to bind RAGE and induce NF-kB activation. However, NF-kB activation was greatly increased when the same concentration of fibrillar TTR was added to the cells (Fig. 5A, lanes 6 and 7), and this effect was not blocked by the presence of RBP (Fig. $5 A$, lane 8). NF-kB activation was prevented when cells were pretreated with anti-RAGE IgG, which leads to receptor blockade (Fig. 5A, lane 9), whereas the same amount of nonimmune IgG did not affect activation (Fig. 5A, lane 10). Mock-transfected cells were used as controls for the experiment, and no NF-kB activation in the presence of TTR fibrils was observed (data not shown). To determine if NF-kB activation might be occurring in tissues of patients with FAP, samples were analyzed immunohistochemically for nuclear translocation of NF-kBp50. Increased p50 
$\mathbf{A}$

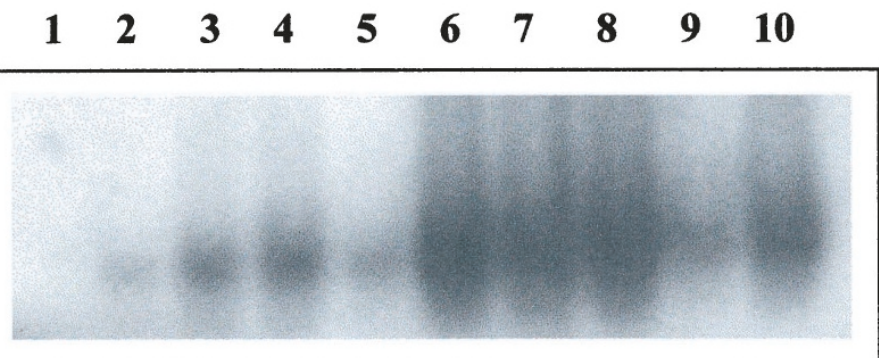

B $\begin{array}{ll}\text { FAP CONTROL } & \text { COP }\end{array}$

NERVE

LUNG

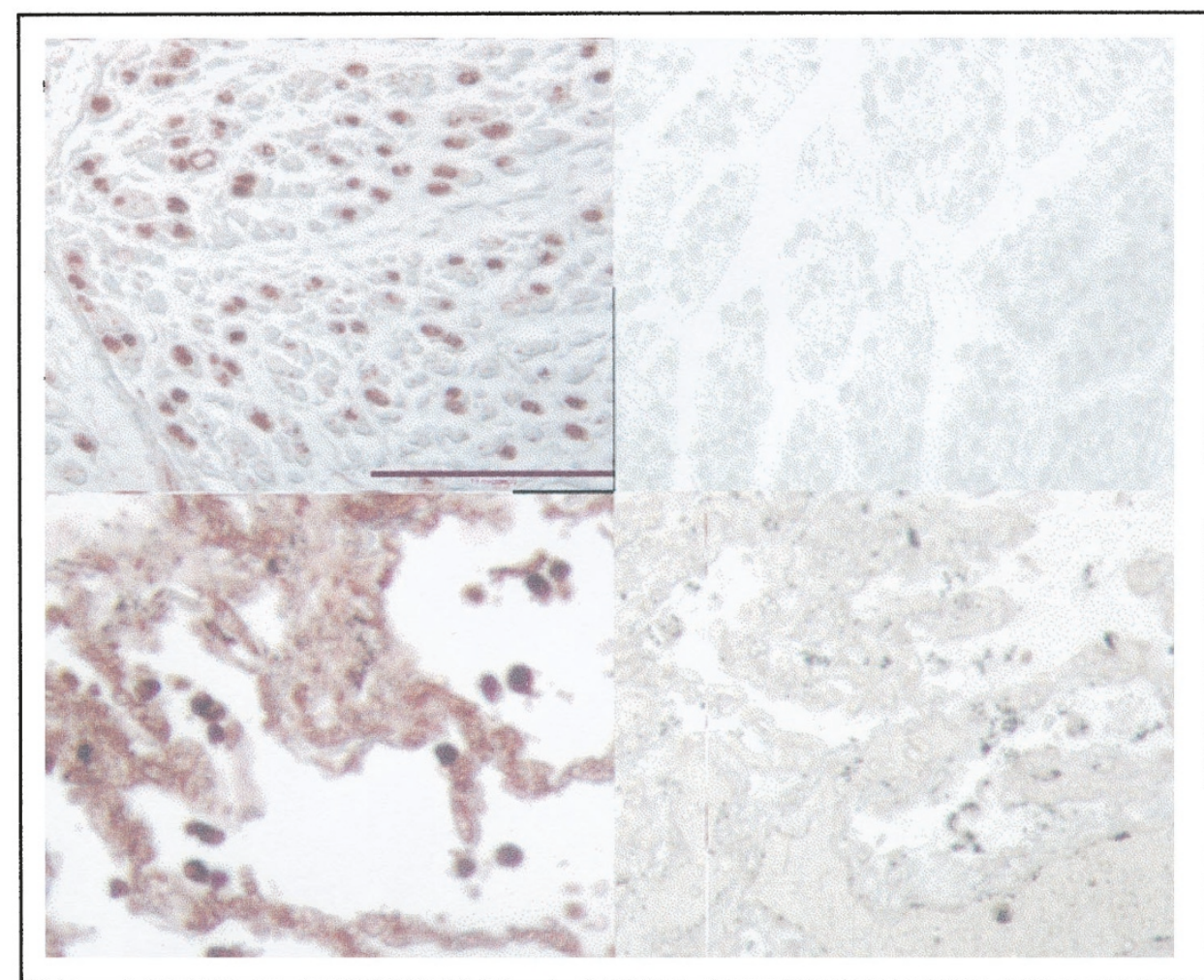

\section{Figure 5.}

A, Activation of nuclear transcription factor kB (NF-kB) in PC12 cells stably transfected with RAGE and exposed to $15 \mu \mathrm{g}$ TTR fibrils and 100 -fold molar excess unlabeled NF-kB probe (1), cell media only (2), $5 \mu \mathrm{g} / \mathrm{ml}$ soluble TTR (3), $15 \mu \mathrm{g} / \mathrm{ml}$ soluble TTR (4), $15 \mu \mathrm{g} / \mathrm{ml}$ soluble TTR complexed with RBP (5), $5 \mu \mathrm{g} / \mathrm{ml}$ TTR fibrils (6), $15 \mu \mathrm{g} / \mathrm{ml}$ TTR fibrils (7), $15 \mu \mathrm{g} / \mathrm{ml}$ TTR fibrils incubated with RBP (8), anti-RAGE IgG (15 $\mu \mathrm{g} / \mathrm{ml})$ (9), and nonimmune IgG (15 $\mu \mathrm{g} / \mathrm{ml})$ (10). B, p50 immunostaining of FAP (left panels) and non-FAP control (right panels), nerve (upper panels) and lung (lower panels) sections.

staining was observed in a nuclear distribution in both nerve and lung samples from the patients with FAP (Fig. 5B, left panels), versus low levels of immunoreactivity in control tissue samples (Fig. 5B, right panels). Taken together, these results indicate that binding of TTR fibrils to RAGE results in activation and nuclear translocation of NF-kB.

\section{Discussion}

This report demonstrates that RAGE acts as a cellsurface receptor for transthyretin. Both soluble and fibrillar TTR bind RAGE in a dose-dependent, specific, and saturable fashion with an apparent $\mathrm{K}_{\mathrm{d}}$ of approximately $120 \mathrm{~nm}$. Binding is inhibited in the presence of
anti-RAGE IgG and sRAGE. The TTR-RAGE interaction was confirmed on $\mathrm{CHO}$ cells expressing RAGE, indicating that RAGE is a binding site for TTR on cellular surfaces. It is important to note that the results obtained on the binding assays are not because of the iodination itself of TTR; binding assays performed with 125J-RAGE and nonlabeled TTR (Fig. 3B, assessment of RAGE interaction with soluble and fibrillary TTR) had essentially the same results as assays performed with ${ }^{125} \mathrm{I}-$ TTR and nonlabeled RAGE (Fig. 2). Also, nonlabeled TTR is able to displace binding of ${ }^{125} \mathrm{I}-\mathrm{TTR}$ to RAGE (Fig. 2B), thus showing that the native nondamaged form of the protein is able to interact with the receptor. Further evidence excluding the role 
of iodination damage in enhancing the interaction of proteins with RAGE is the fact that several proteins when iodinated, do not bind this receptor, as is the case of native albumin and native $\beta_{2}$-microglobulin, whereas their iodinated advanced glycation end products do (Miyata et al, 1996; Schmidt et al, 1994).

Because RAGE is essentially a scavenger receptor, one would expect that TTR would be sequestered by the receptor only when in a damaged conformation, but our results clearly show that, in vitro, both the native and the modified form of the protein interact with RAGE. Nevertheless, under physiological conditions, where soluble plasma TTR circulates bound to RBP, the interaction of the complex TTR-RBP with RAGE is probably absent, as suggested by our data. This might be caused by steric hindrance of the RBP molecule on the surface of TTR. Alternatively, both RAGE and RBP might share overlapping binding sites on the TTR molecule. It has been recently shown that RBP binds at a 2-fold symmetry in the TTR tetramer (Naylor and Newcomer, 1999). Four aminoacids on TTR (Arg21, Val20, Leu82, and Ile84) are contributed by two monomers and constitute the RBP recognition site. Physiologically, RAGE would not ordinarily encounter free TTR. However, in pathological conditions when TTR forms fibrils, it loses the ability to combine with RBP, and binding to RAGE is favored as evidenced by our results. Also, it is possible that other putative TTR ligands may exert the same effect in vivo as demonstrated here for the case of RBP.

TTR is known to be a tetrameric protein composed of four identical subunits. Each TTR monomer contains eight strands that form two sheets of four strands each and are arranged in a topology similar to the classic Greek key barrel. However, TTR fibrils are not likely to be made up of the native tetrameric form, and transition may occur in which monomers are modified into a pathological conformation (Quintas et al, 1999; Sebastião et al, 1998). Bearing in mind other described ligands for RAGE (A $\beta$, amylin, serum amyloid $A$, and prion protein) and the high $\beta$ sheet content of TTR, this seems to indicate that this receptor is prone to recognize $\beta$ sheet structures, which, in the case of TTR, might be present in both the soluble and fibrillar form.

RAGE has high homology to the neural cell adhesion molecule and Muc-18 (Neeper et al, 1992). The extracellular domain is comprised of three immunoglobulin-like regions, including one $\mathrm{N}$-terminal V-type domain, followed by two C-type domains. The remainder of the molecule is made up of a single transmembrane spanning domain and a short cytosolic tail at the C-terminus. No crystallographic data have been obtained for this molecule, and future experiments should aim at solving the three dimensional structure of RAGE.

In Alzheimer's disease, generation of reactive oxygen intermediates, induction of cytotoxic cellular oxidant stress, and promotion of microglial activation occur (Giulian et al, 1995; Klegeris et al, 1994; McGeer et al, 1993). Some of these effects may be facilitated by $A \beta$ binding to RAGE. RAGE has also been shown recently to serve as a signal transduction receptor for members of the S100/calgranulin family (Hofmann et al, 1999).

Oxidative stress in human amyloid deposits from patients with FAP has been examined immunohistochemically, using two markers of lipid peroxidation, antihydroxynonenal, and thiobarbituric acid reactive substances (Ando et al, 1997). Furthermore, the levels of protein carbonyl, a marker of protein modifications by free radicals, were determined in FAP patients and healthy controls (Ando et al, 1997). Antihydroxynonenal antibody reacted with amyloid deposits in all types of amyloid tissues examined, and significantly higher levels of thiobarbituric acid reactive substances and protein carbonyl were found in amyloid rich tissues of FAP patients than in the control subjects. These results suggest that lipid peroxidation, via free radical injury, occurs in amyloid deposits in FAP. Whether these effects are triggered upon binding of fibrils to RAGE remains to be investigated.

We hypothesized that similar to what may happen in Alzheimer's disease, binding of TTR to RAGE would result in altered gene expression and cellular properties, such as induction of the transcription factor NF-kB. The NF-kB transcription factor complex is a pleiotropic activator that participates in the induction of wide variety of genes. The active complex is composed of two subunits, p50 and p65. We demonstrated that TTR fibrils can bind cell surface RAGE and modulate cellular properties, at least in part, through activation of the transcription factor NF-kB. Though soluble TTR is able to induce NF-kB expression, the effect is less than that produced by the same concentration of TTR fibrils, and it is reduced to background levels when the soluble protein is complexed with RBP. In FAP tissues we found activation of NF-kB, based on nuclear localization and up-regulation of p50, when compared to non-FAP control tissues. Such NF-kB activation might contribute to increased expression of macrophage-colony stimulating factor, interleukin-6, hemeoxygenase type 1, and other inflammation-associated molecules. In FAP, further investigation is needed to address this issue.

Although constitutive expression of RAGE was found in all of the control individuals, increased expression of RAGE in FAP tissues was observed. This indicates that this receptor may be relevant to the cellular dysfunction in the disorder. A likely explanation for the apparent juxtaposition of TTR deposits with cells expressing high levels of RAGE is that TTR-RAGE interaction triggers activation of NF-kB, which, via the NF-kB DNA binding elements in the RAGE promoter, up-regulates RAGE expression ( $\mathrm{Li}$ and Schmidt, 1997). Increased levels of receptor promote further TTR-RAGE interaction, thereby propagating the cytotoxic effects of RAGE.

Although these studies represent only a first step in establishing a link between expression of RAGE and patophysiological changes in FAP, they suggest a mechanism in which engagement of RAGE in the presence of TTR fibrils could result in deleterious consequences for cellular function and organic ho- 
meostasis. If this hypothesis is correct, blocking access of TTR to this cell surface binding site might considerably retard progression of cellular dysfunction.

\section{Materials and Methods}

\section{Proteins}

Recombinant RAGE, comprising the extracellular domain of the receptor (termed soluble RAGE or sRAGE), was expressed using baculovirus and purified to homogeneity as described (Hori et al, 1995). Recombinant TTR was purified from Escherichia coli D1210 transformed with plasmids carrying wild-type TTR cDNA, as described by Almeida et al (1997). Serum RBP (1 $\mathrm{mg} / \mathrm{ml})$ was isolated using a TTR affinity column and saturated with $3.3 \mathrm{mg} / \mathrm{ml}$ of all-trans retinol (Sigma, St. Louis, Missouri) in ethanol by incubation at $37^{\circ} \mathrm{C}$ in the dark for 1 hour. Excess of retinol was separated from RBP by gel filtration in $10 \mathrm{ml}$ columns of Biogel P-6 DG (Bio-Rad, Richmond, California). The TTR:RBP complex was formed by incubation of TTR and RBP in a 1:4 molar ratio for 1 hour at $37^{\circ} \mathrm{C}$ in the dark. TTR fibrils were generated from soluble wt TTR $(2 \mathrm{mg} / \mathrm{ml})$ by incubation with $0.05 \mathrm{M}$ sodium acetate $/ 0.1 \mathrm{M} \mathrm{KCl}, \mathrm{pH} 3.6$, for 48 hours at room temperature (Bonifácio et al, 1996).

For binding studies, sRAGE and TTR were iodinated using IODOBEADS (Pierce Chemical Company, Rockford, Illinois) following the manufacturer's instructions. The reaction mixture was subsequently desalted by gel filtration. ${ }^{125} \mathrm{I}$-labeled proteins were more than 95\% precipitable in trichloroacetic acid and homogeneous on SDS-PAGE.

Monospecific rabbit antihuman RAGE IgG was prepared using human SRAGE as the immunogen and characterized as described (Brett et al, 1993). Nonimmune lgG was obtained by purification on a protein $A$ column.

\section{Immunohistochemistry}

Biopsy and/or autopsy material from Val30Met TTR FAP patients with proven amyloid deposition was fixed in $4 \%$ neutral buffered formalin solution at room temperature for 2 hours. Paraffin embedded sections were cut (20 $\mu \mathrm{m}$ thick), deparaffinated for 30 minutes in xylol, and dehydrated in a modified alcohol series (100\%, 90\%, 80\%, and 70\%, 10 minutes each). For anti-RAGE immunohistochemistry, sections were incubated in blocking buffer (1\% bovine serum albumin and $4 \%$ goat serum) for 30 minutes at $37^{\circ} \mathrm{C}$ in a moist chamber. Subsequently, incubation with anti-RAGE IgG (1:75 diluted in blocking buffer) at $4^{\circ} \mathrm{C}$ was performed overnight. Antigen visualization was performed as described by Yan et al (1996). For TTR immunostaining, sections were treated with rabbit anti-TTR (DAKO, Carpinteria, California), 1:100 diluted in blocking solution, for 3 hours at room temperature, followed by incubation with antirabbit IgG horseradish peroxidase (The Binding Site), 1:200 diluted in blocking buffer, for an additional 1 hour at room tempera- ture. Peroxidase activity was visualized with 3,3'diaminobenzidine $/ \mathrm{H}_{2} \mathrm{O}_{2}$, and the sections were counterstained with Gill's hematoxylin. On parallel control sections, primary antibody was replaced by blocking buffer. p50 immunohistochemistry was performed as described by Yan et al (1995). The immunohistochemistry results were evaluated independently by two investigators and, according to the staining intensity, blindly scored as negative (-), faintly positive $(+)$, and positive $(++)$. The score applied refers to the staining intensity and not to the frequency of positive cell types. For histochemical demonstration of amyloid, paraffin sections were stained with Congo red.

\section{Binding of TTR to RAGE}

For binding of soluble ${ }^{125}$ I-TTR to RAGE, 96 well plates (Maxisorp; Nunc, Rochester, New York) were coated overnight with $5 \mu \mathrm{g} /$ well of sRAGE unless stated otherwise. The indicated concentration of $s^{125} I-$ TTR was incubated with the plates alone or with 100-fold molar excess unlabeled TTR in binding buffer (0.1\% skim milk in minimal essential medium-MEM [Gibco, Gaithersburg, Maryland]) for 2 hours at $37^{\circ} \mathrm{C}$ with gentle shaking. Binding was determined after five washes in ice-cold PBS with $0.05 \%$ Tween 20 (0.2 $\mathrm{ml} /$ wash). Then, $0.1 \mathrm{ml}$ elution buffer $(\mathrm{NaCl} 0.1 \mathrm{M}$ containing $1 \%$ nonidet P40) was added for 5 minutes at $37^{\circ} \mathrm{C}$, and the contents of the wells were aspirated and counted in a Rackgamma counter. For comparative binding of fibril and soluble TTR (sTTR) (alone or complexed with RBP), plates were coated with these proteins and ${ }^{125} \mathrm{I}$-sRAGE was added alone or with 100 -fold molar excess of unlabeled sRAGE. Binding was carried out as described above. For competition studies employing rabbit antihuman RAGE IgG, nonimmune rabbit IgG or sRAGE were added at the indicated concentration. Specific binding was defined as that observed with ${ }^{125} \mathrm{I}$ labeled protein alone minus ${ }^{125} \mathrm{I}$ labeled protein in the presence of 100 -fold molar excess unlabeled. Experiments were repeated a minimum of four independent times, and representative results are shown. Binding data were fit to a one-site model and analyzed by the method of Klotz and Hunston (1984).

\section{Binding of ${ }^{125}$ I-TTR to RAGE Transfected Cells}

Transient transfection of $\mathrm{CHO}$ cells (American Type Cell Collection) was performed with Lipofectamine (Life Technologies, Inc., Rockville, Maryland) according to the manufacturer's recommendations. Briefly, $3 \times 10^{5}$ cells were plated into $100 \mathrm{~mm}$ tissue culture plates 1 day before the transfection. The DNA used for transfection was the pcDNA3 plasmid carrying human RAGE cDNA. Mock transfections with pcDNA3 alone were performed as control. Cells were exposed to the mixture of Lipofectamine and plasmid for 5 hours. After removal of the transfection reagent, fresh medium was added and the incubation continued for 48 hours. Radioligand binding studies were performed 
using RAGE-transfected $\mathrm{CHO}$ cells and also PC12 cells stably expressing human RAGE (Yan et al, 1996). $\mathrm{CHO}\left(7.5 \times 10^{4}\right.$ cells/well at the time of plating) were grown to confluence in 96 well plates previously coated with $0.2 \%$ gelatin and washed three times in Hank's balanced salt solution, $\mathrm{pH}$ 7.4. Binding was carried out essentially as described in the previous section. For studies employing antibodies and nonimmune IgG, cells were pre-incubated for 15 minutes at $4^{\circ} \mathrm{C}$ with the indicated amount of antibody or nonimmune lgG, and, subsequently, the radioligand binding assay was performed. Data assessment was performed as described above.

\section{Electrophoretic Mobility Shift Assay}

Nuclear extracts were prepared by the method of Dignam et al (1983) from PC12 cells stably transfected with RAGE cDNA using the procedure described by Yan et al (1996). Cells were exposed for 5 hours at $37^{\circ} \mathrm{C}$ to 5 or $15 \mu \mathrm{g} / \mathrm{ml}$ of soluble or fibrillar TTR in the presence and absence of RBP. Briefly, cells were scraped in 0.6\% NP40, $150 \mathrm{~mm} \mathrm{NaCl}, 10 \mathrm{~mm}$ HEPES, $\mathrm{pH} 7.9,1 \mathrm{~mm}$ EDTA, and $0.5 \mathrm{~mm}$ phenylmethylsulfonyl fluoride, after which the DNA-binding proteins were extracted using 25\% glycerol, $20 \mathrm{~mm}$ HEPES, $420 \mathrm{~mm}$ $\mathrm{NaCl}, 1.2 \mathrm{~mm} \mathrm{MgCl}$, $0.12 \mathrm{~mm}$ EDTA, and $0.5 \mathrm{~mm}$ DTT in the presence of protease inhibitors. Where indicated, cultures were pretreated for 3 hours with 15 $\mu \mathrm{g} / \mathrm{ml}$ of anti-RAGE or nonimmune rabbit IgG. Human consensus NF-kB oligonucleotide (Promega, Madison, Wisconsin) was 5'end-labeled using T4 polynucleotide kinase via standard procedures. Binding reactions were performed by pre-incubating nuclear extract proteins in $20 \mathrm{~mm}$ HEPES, $60 \mathrm{~mm} \mathrm{KCl,} 1 \mathrm{~mm}$ $\mathrm{MgCl}_{2}, 0.1 \mathrm{M}$ EDTA, $10 \%$ glycerol, and $0.5 \mathrm{~mm}$ dithiotreitol on ice for 10 minutes, followed by the addition of $\gamma^{32} \mathrm{P}$-labeled oligonucleotide and a second incubation at room temperature for 20 minutes. Samples were loaded directly onto nondenaturing $6 \%$ polyacrylamide gels (29:1 acrylamide to bisacrylamide) prepared in Tris (45 mm), boric acid (45 mm), EDTA (0, $1 \mathrm{M})($ TBE $0.5 \times)$. Electrophoresis was performed at room temperature for 2 hours at 100 V. Gels were exposed to Hyperfilm MP (Amersham, Arlington Heights, Illinois) with intensifying screens. For competition experiments, a 100-fold molar excess of unlabeled probe was used.

\section{Acknowledgements}

We thank the excellent technical support of Rui Fernandes in the immunohistochemistry studies and Paul Moreira in the production of recombinant TTR.

\section{References}

Almeida MR, Damas AM, Lans MC, Brouwer A, and Saraiva MJ (1997). Thyroxine binding to transthyretin Met 119. Comparative studies of different heterozygotic carriers and structural analysis. Endocrine 6:309-315.

Ando Y, Nyhlin N, Suhr O, Holmgren G, Uchida K, el Sahly M, Yamashita T, Terasaki H, Nakamura M, Uchino M, and Ando
M (1997). Oxidative stress is found in amyloid deposits in systemic amyloidosis. Biochem Biophys Res Commun 232: 497-502.

Behl C, Davis J, Lesley R, and Schubert D (1994). Hydrogen peroxide mediates amyloid beta protein toxicity. Cell $77: 817-$ 827.

Blake CCF, Geisow MJ, Swan ID, Rerat C, and Rerat B (1974). Structure of human plasma prealbumin at 2-5 A resolution. A preliminary report on the polypeptide chain conformation, quaternary structure and thyroxine binding. $J$ Mol Biol 88:1-12.

Boland K, Behrens M, Choi D, Manias K, and Perlmutter DH (1996). The serpin-enzyme complex receptor recognizes soluble, nontoxic amyloid-beta peptide but not aggregated, cytotoxic amyloid-beta peptide. J Biol Chem 271:1803218044.

Bonifácio MJ, Sakaki Y, and Saraiva MJ (1996). "In vitro" amyloid fibril formation from transthyretin: The influence of ions and the amyloidogenicity of TTR variants. Biochim Biophys Acta 1316:35-42.

Brett J, Schmidt AM, Zhou YS, Yan SD, Weidman E, Pinsky D, Neeper M, Przysiecki C, Shaw A., Migheli A, and Stern D (1993). Survey of the distribution of a newly characterized receptor for advanced glycation end products in tissues. Am J Pathol 143:1699-1712.

Dignam J, Lebovitz R, and Roeder R (1983). Accurate transcription initiation by RNA polymerase II in a soluble extract from isolated mammalian nuclei. Nucleic Acids Res 11:14751489.

Du Yan S, Zhu H, Fu J, Yan SF, Roher A, Tourtellotte WW, Rajavashisth T, Chen X, Godman GC, Stern D, and Schmidt AM (1997). Amyloid-beta peptide-receptor for advanced glycation endproduct interaction elicits neuronal expression of macrophage-colony stimulating factor: A proinflammatory pathway in Alzheimer disease. Proc Natl Acad Sci USA 94:5296-5301.

Giulian D, Haverkamp L, Li J, Karshin Y, Yu J, Tom D, Li X, and Kirkpatrick J (1995). Senile plaques stimulate microglia to release a neurotoxin found in Alzheimer brain. Neurochem Int 27:119-137.

Giulian D, Haverkamp LJ, Yu J, Karshin W, Tom D, Li J, Kazanskaia A, Kirkpatrick J, and Roher AE (1998). The HHQK domain of beta-amyloid provides a structural basis for the immunopathology of Alzheimer's disease. J Biol Chem 273: 29719-29726.

Gustavsson A, Jahr H, Tobiassen R, Jacobson DR, Sletten K, and Westermark P (1995). Amyloid fibril composition and transthyretin gene structure in senile systemic amyloidosis. Lab Invest 73:703-708.

Hensley K, Carney J, Mattson M, Aksenova M, Harris M, Wu J, Floyd R, and Butterfield D (1994). A model for beta-amyloid aggregation and neurotoxicity based on free radical generation by the peptide: Relevance to Alzheimer disease. Proc Natl Acad Sci USA 91:3270-3274.

Hofmann M, Drury S, Caifeng F, Qu W, Taguchi A, Lu Y, Avila C, Kambhan N, Slattery T, Beach D, McClary J, Nagashima M, Morser J, Nawroth P, Stern D, and Schmidt AM (1999). RAGE mediates a novel proinflammatory axis: A central cell surface receptor for $\mathbf{S 1 0 0 / c a l g r a n u l i n}$ polypeptides. Cell 97: 889-901. 
Hori O, Brett J, Slattery T, Cao R, Zhang J, Chen JX, Nagashima M, Lundh ER, Vijay S, and Nitecki D (1995). The receptor for advanced glycation end products (RAGE) is a cellular binding site for amphoterin. Mediation of neurite outgrowth and co-expression of rage and amphoterin in the developing nervous system. J Biol Chem 270:25752-25761.

Kindy M, Hong D, Schmidt AM, Stern D, and Yan SD (1999). Soluble RAGE decreases splenic cellular activation and accumulation in a murine model of systemic amyloidosis. Society for Neuroscience, vol 25 (part II):1566 (abstract).

Kislinger T, Fu C, Qu W, Yan S, Hofmann M, Pieschetstrieder M, Stern D, and Schmidt AM (1999). N(epsilon)(carboxymethyl)lysine adducts of proteins are ligands for receptor for advanced glycation end products that activate cell signaling pathways and modulate gene expression. J Biol Chem 274:31740-31749.

Klegeris A, Walker D, and McGeer P (1994). Activation of macrophages by Alzheimer beta amyloid peptide. Biochem Biophys Res Commun 199:984-991.

Klotz I and Hunston D (1984). Mathematical models for ligand-receptor binding. Real sites, ghost sites. J Biol Chem 259:10060-10062.

LaFerla FM, Troncoso JC, Strickland DK, Kawas CH, and Jay G (1997). Neuronal cell death in Alzheimer's disease correlates with apoE uptake and intracellular Abeta stabilization. J Clin Invest 100:310-320.

Li J and Schmidt AM (1997). Characterization and functional analysis of the promoter of RAGE, the receptor for advanced glycation end products. J Biol Chem 272:16498-16506.

Matter M, Zhang Z, Nordstadt C, and Ruoslahti E (1998). The alpha- 5 beta- 1 integrin receptor binds the Alzheimer disease amyloid-beta protein and mediates its internalization. Keystone Symp Proc X5, 101 (abstract).

McGeer P, Kawamata T, Walker D, Akiyama H, Tooyama I, and McGeer E (1993). Microglia in degenerative neurological disease. Glia 7:84-92.

Miyata T, Hori O, Zhang J, Yan SD, Ferran L, lida $Y$ and Schmidt AM (1996). The receptor for advanced glycation end products (RAGE) is a central mediator of the interaction of AGE- $\beta_{2}$ microglobulin with human mononuclear phagocytes via an oxidative-sensitive pathway. J Clin Invest 5:10881094.

Naylor HM and Newcomer ME (1999). The structure of human retinol-binding protein (RBP) with its carrier protein transthyretin reveals an interaction with the carboxy terminus of RBP. Biochemistry 38:2647-2653.

Neeper M, Schmidt AM, Brett J, Yan SD, Wang F, Pan YC, Elliston K, Stern D, and Shaw A (1992). Cloning and expression of a cell surface receptor for advanced glycosylation end products of proteins. J Biol Chem 267:14998-15004.

Quintas A, Saraiva MJ, and Brito RM (1999). The tetrameric protein transthyretin dissociates to a non-native monomer in solution. A novel model for amyloidogenesis. J Biol Chem 274:32943-32949.

Raz A, Shiratori T, and Goodman DS (1970). Studies on the protein-protein and protein-ligand interactions involved in retinol transport in plasma. J Biol Chem 245:1903-1912.

Saraiva MJ (1995). Transthyretin mutations in health and disease. Hum Mutat 5:191-196.
Saraiva MJ, Birken S, Costa PP, and Goodman DS (1983). Amyloid fibril protein in familial amyloidotic polyneuropathy, Portuguese type. Definition of molecular abnormality in transthyretin (prealbumin). J Clin Invest 74:104-119.

Schmidt AM, Vianna M, Gerlach M, Brett J, Ryan J, Kao J, Esposito C, Hegarty H, Hurley W, Clauss M, Wang F, Pan Y, Tsang T, and Stern D (1992). Isolation and characterization of two binding proteins for advanced glycosylation end products from bovine lung which are present on the endothelial cell surface. J Biol Chem 267:14987-14997.

Schmidt AM, Hasu M, Popov D, Zhang JH, Chen J, Yan SD, Brett J, Cao R, Kuwabara K, Costache G, Simionescu N, Simionesco M, and Stern SD (1994). Receptor for advanced glycation end products (AGEs) has a central role in vessel wall interactions and gene activation in response to circulating AGE proteins. Proc Natl Acad Sci USA 91:8807-8811.

Schmidt AM, Yan S, Wautier J, and Stern D (1999). Activation of receptor for advanced glycation end products: A mechanism for chronic vascular dysfunction in diabetic vasculopathy and atherosclerosis. Circ Res 84:489-497.

Sebastião MP, Saraiva MJ, and Damas AM (1998). The crystal structure of amyloidogenic Leu55 -> Pro transthyretin variant reveals a possible pathway for transthyretin polymerization into amyloid fibrils. J Biol Chem 273:2471524722.

Selkoe DJ (1999). Translating cell biology into therapeutic advances in Alzheimer's disease. Nature 399:A23-A31.

Shen Y, Yang L-B, Lue L-F, and Rogers J (1998). p55 and p75 TNF receptor subtypes bind amyloid beta-peptide and are differentially expressed in the Alzheimer's brain. Neurobiol Aging 19:S45:\#188-S45:\#180 (abstract).

Sisodia SS and Price DL (1995). Role of the beta-amyloid protein in Alzheimer's disease. FASEB J 9:366-370.

Smith M, Perry G, Richey P, Sayre L, Anderson V, Beal M, and Kowall N (1996). Oxidative damage in Alzheimer's. Nature 382:120-121.

Yaar M, Zhai S, Pilch PF, Doyle SM, Eisenhauer PB, Fine RE, and Gilchrest BA (1997). Binding of beta-amyloid to the p75 neurotrophin receptor induces apoptosis. A possible mechanism for Alzheimer's disease. J. Clin. Invest. 100:23332340 .

Yan SD, Chen X, Fu J, Chen X, Zhu H, Roher A, Slattery T, Zhao L, Nagashima M, Morser J, Migheli A, Nawroth P, Stern D, and Schmidt AM (1996). RAGE and amyloid-beta peptide neurotoxicity in Alzheimer's disease. Nature 382:685-691.

Yan SD, Yan SF, Chen X, Fu J, Chen M, Kuppusamy P, Smith MA, Perry G, Godman GC, Nawroth P, Zweier JL, and Stern D (1995). Non-enzymatically glycated tau in Alzheimer's disease induces neuronal oxidant stress resulting in cytokine gene expression and release of amyloid beta-peptide. Nat Med 1:693-699.

Yan SD, Zhu H, Zhu A, Golambek A, Soto C, Roher A, Chaney M, Stern D, and Schmidt AM (1999). RAGE is a signal transduction receptor for beta-sheet fibrils: Receptor dependent promotion of A-beta fibril formation, cell surface binding and cellular activation. Society for Neuroscience, vol 25 (part II):1296 (abstract). 